\title{
An Empirical Study on the Growth of Agricultural Green Total Factor Productivity in the Huanghuai River Economic Zone by Big Data Computing
}

\author{
Yanan Zhang $\mathbb{D},{ }^{1}$ Jinghong Wei, ${ }^{1}$ Ying Wang, ${ }^{1}$ and Sang-Bing Tsai $\mathbb{D}^{2}$ \\ ${ }^{1}$ College of Economics and Management, Hebei Agricultural University, Hebei 071000, China \\ ${ }^{2}$ Regional Green Economy Development Research Center, School of Business, Wuyi University, Nanping, China \\ Correspondence should be addressed to Yanan Zhang; hbndzyn1019@163.com
}

Received 12 November 2021; Revised 7 December 2021; Accepted 15 December 2021; Published 6 January 2022

Academic Editor: Xiao Xue Zheng

Copyright ( $) 2022$ Yanan Zhang et al. This is an open access article distributed under the Creative Commons Attribution License, which permits unrestricted use, distribution, and reproduction in any medium, provided the original work is properly cited.

Facing the new form and situation of the Huaihe Economic Zone, it is of great significance to analyze the sources of growth and the intrinsic mechanism of the green total factor productivity of its economic-ecological system, to grasp the spatial and temporal characteristics of green total factor productivity, and to study the influence of each factor on green total factor productivity to achieve sustainable economic development in the Huaihe Economic Zone. Based on the clarification of economic growth theory, green economy theory, carbon cycle theory, and green total factor productivity theory, this paper identifies and discusses the limitation that the existing research literature often ignores the endogenous role of carbon sinks when measuring green total factor productivity. Then, the green total factor productivity of Huaihe Economic Zone based on carbon cycle from 2004 to 2017 is measured using the superefficient nonradial SBM model. Combined with the GML productivity index, it is decomposed into technical progress and technical efficiency and analyzed in comparison with the green total factor productivity without considering ecological purification capacity (carbon sink) from the perspective of time and space. Finally, the spatial Durbin model is used to analyze the effects of seven variables, including the level of economic development, environmental regulation, R\&D level, and openness to the outside world, on green total factor productivity in the Huaihe Economic Zone, and to analyze the direct and indirect effects of each variable on green total factor productivity. TFP based on expected output carbon sink and GDP overall outperforms TFP based on expected output GDP only, mainly because the growth of technical efficiency is underestimated when carbon sink is not considered. Technical efficiency and technological progress are equally important for the growth of TFP in an eco-economic perspective. It is of great practical significance for both the comprehensive understanding of the green total factor productivity level and the improvement path of the ecosystem and the coordinated and sustainable development of the Huaihe Economic Zone.

\section{Introduction}

In today's world, global warming induced by greenhouse gas emissions is threatening the survival and development of human beings, which makes people pay attention to the resource and environmental problems caused by rapid economic development, and economic development has changed from simply pursuing capital and labor efficiency to pursuing resource and environmental efficiency, and green and low-carbon development has become an inevitable option for all countries in the world [1]. As a responsible world power, China has clearly proposed in its national independent contribution document that, by 2030 , carbon dioxide emissions per unit of GDP will drop by $60 \%-65 \%$ compared to 2005, nonfossil energy will account for about $20 \%$ of primary energy consumption, forest stock will increase by 4.5 billion cubic meters compared to 2005, and carbon dioxide emissions will peak around 2030 and strive to reach the peak as early as possible. Emissions will peak by 2030 and reach the peak as soon as possible [2]. The economic development and the resources and environment are in intense contradiction, and the rough industrial growth 
model is causing great damage and pollution to the ecological environment, and the green and sustainable economic development and social progress will be seriously affected [3]. Therefore, attention has to be paid to the issue of coordinated sustainable development between economy and resources and environment [4]. Both the current environmental pollution problems brought by the rapid economic development of Huaihe Economic Zone and the importance of the government of Huaihe Economic Zone to the issue of green sustainable development show the importance of coordinated economic-resource-environment sustainable development [5].

The Huaihe Economic Zone includes 11 provinces and cities in Shanghai, Jiangsu, and Zhejiang, spanning the three regions of east, west, and central China, with the 21st Century Maritime Silk Road in the east and the Silk Road Economic Zone in the west [6]. It is a coordinated development zone of east-west interaction and cooperation, an inland economic zone with global influence, and an internal and external opening zone for coastal cities along the border and rivers and is called the "backbone of China's economy" in the future. As a typical representative of the river basin economy, major projects such as automobiles, petrochemicals, and electromechanics are laid out to contribute to economic growth [7]. The Huaihe Economic Zone supports more than $45 \%$ of the country's economic output with about $20 \%$ of its land area. In 2014, the State Council made it clear, for the first time, that the strategic positioning of the Huaihe Economic Zone is "a pioneering demonstration zone for ecological civilization construction." The report of the 19th Party Congress also clearly put forward the concept of "grasping big protection and not big development" to promote the green and sustainable development of the Huaihe Economic Zone with minimum resource consumption and active environmental protection [8]. At the same time, General Secretary Xi Jinping, when inspecting the development of the Huaihe Economic Zone, clearly proposed that the Huaihe Economic Zone must take the path of ecological priority and green development and that all economic activities should not be based on the premise of damaging the ecological environment, so as to correctly grasp the relationship between ecological environmental protection and coordinated economic development and build a pioneering demonstration zone for green economic development [9]. This means that the high-speed economic growth model, which consumes a lot of resources and energy and leads to environmental pollution, needs to be transformed into a green sustainable development model, in which economic growth, resource conservation, and environmental protection are coordinated in parallel. In the current context of emphasizing the coexistence of efficient economic growth and environmental protection, there is an urgent need to solve the problem of coordinated and parallel economic growth, resource conservation, and environmental protection in the Huaihe Economic Zone in order to achieve green economic development [10]. Among them, green total factor productivity comprehensively reflects the actual level of coordinated development among economic growth, resource conservation, and environmental protection. It is also necessary to further explore the impact of factors such as the level of economic development, environmental regulation, openness to the outside world, R\&D level, industrial structure, and urbanization on the issues of resource allocation, energy consumption, and environmental protection [11]. Therefore, under the reality that economic development has brought about massive consumption of resources and energy and environmental pollution, an in-depth study on the measurement and mechanism of the role of green total factor productivity is of great practical significance for the green and sustainable development of the economic-resource-environment system [12].

Therefore, this paper discusses the role of carbon sink as an endogenous variable of green total factor productivity and the influence of each factor on green total factor based on a comprehensive measurement of green total productivity in the Huaihe Economic Zone provinces considering the carbon cycle capacity of ecosystems, which enriches the theoretical system of China's economic growth and makes up for the deficiency of neglecting carbon sink on green total productivity measurement, thus improving the theoretical system of sustainable development. The endogenous role of carbon sinks on green total factor productivity in each region is revealed, and the source of green total factor productivity growth in the Huaihe Economic Zone is studied, which helps realize the green economic growth with the coordination of economy, resources, and environment in the Huaihe Economic Zone.

(1) By incorporating economic development level, environmental regulation, scientific research level, industrial structure, openness to the outside world, urbanization, and infrastructure into the framework of influencing factor research, and then exploring how each factor affects green total factor productivity by what mechanism.

(2) Besides, we also reveal the similarities and differences of green economic development in each region of the Huaihe Economic Zone and provide relevant policy recommendations.

(3) Finally, we proposed a comprehensive understanding of the economic-ecological system's green total factor productivity level.

\section{Related Work}

Growth rate is an indicator of the speed of a country's development, while productivity is an indicator of the quality of development. Earlier studies of productivity mainly reflected single factor productivity, that is, the growth of output caused by a particular factor of production, for example, labor productivity and capital productivity. Labor productivity is the productivity of workers, which is the ratio of output created by workers in a certain period to the amount of labor consumed in that period. Capital productivity is the productivity of capital, which is the ratio 
of the output created by capital in a certain period to the stock of capital in that period. However, no matter what the kind of single factor productivity is, they only reflect the impact of a certain factor of production on output, which reflects a more one-sided issue. Moreover, there are interactions between different single-factor productivity rates. Therefore, it is difficult to make a scientific judgment on the overall economic development based on a single factor productivity [13]. In his 1957 book "Technical Progress and the Aggregate Production Function," Solow called the residual value of the rate of technical progress after deducting the rate of growth of each input factor from the rate of growth of total factor productivity. According to Cai Fang of the Chinese Academy of Social Sciences, the total factor productivity is the fraction of productivity that exceeds a given level of production efficiency, given that all factor inputs remain constant [14].

For example, if all factors of production such as labor and capital in a factory remain unchanged, but output grows by $5 \%$, then this $5 \%$ is what we call total factor productivity. In recent years, we can clearly feel that, with the development of economy, the problem of overexploitation of resources and environmental pollution is becoming more and more serious; therefore, scholars began to introduce the problem of resources and environment into the study of total factor productivity and called this research to the study of green total factor productivity. Using a stochastic Frontier analysis model beyond the log production function, researchers measured the green total factor productivity and growth trajectory of industrial industries in the Huaihe Economic Zone since the reform and opening up, using labor, capital stock, and energy consumption variables reflecting resource and environmental conditions and carbon dioxide emission variables as input variables and total output value as output variables [15]. The researchers used a combination of SBM directional distance function and Luenberger productivity index, with capital stock, labor, and energy inputs as input variables, total industrial output value as desired output, and pollution emission-related variables as nondesired output and included energy consumption and environmental pollution into the total factor productivity accounting system to measure the green total factor productivity of 39 medium-sized industries in China from 1998 to 2008 [16].

Based on the DEA-Malmquist index method, the researchers measured and compared the traditional total factor productivity without resource and environmental constraints and the green total factor productivity with resource and environmental constraints in China's manufacturing industry, using labor, capital stock, and energy as inputs, total industrial output as desired output, and industrial waste as undesired output. The researcher first uses principal component analysis to select 20 basic indicators from three aspects, environmental pollution, ecological resources, and natural disasters, and then uses them to adjust the traditional GDP to obtain the green GDP [17]. We then use capital stock and labor input as input variables, green GDP as output variables, and nine indicators in five aspects, including economic openness, economic and social structure, and policy system, as external environment variables, and adopt a three-stage DEA model and Malmquist index to analyze the traditional and green total factor productivity of provinces and cities, regions, and time trends in the Huaihe Economic Zone from 2002 to 2009.

The results show that both total factor productivity and green total factor productivity in China's manufacturing industry show a fluctuating upward trend, and their growth is mainly driven by technological progress. Green TFP is relatively high in high-tech and monopolistic industries. In the short run, the increase in the intensity of environmental regulations is beneficial to the increase of green TFP, which also verifies the existence of the "Porter's hypothesis" in China and suggests an environmental regulation path to improve green TFP in manufacturing [18]. The results of the study show that the traditional efficiency evaluation without considering energy, environment, and human capital is significantly distorted, and the green total factor productivity of industry in most provinces is significantly improved by the rate of technological progress, but the change of technical efficiency is not significant, and the difference between different provinces is large [19]. The analysis of the factors influencing the measurement results reveals that there is a significant positive linear correlation between the intensity of environmental regulations and green total factor productivity. The results show that the average growth of green total factor in Huaihe Economic Zone from 1998 to 2011 is $2.07 \%$, and the technological progress is its core driver [20]. The results also indicate that COD emission reduction performance and labor effect contribute to green total factor productivity improvement by the path of technological progress and scale intensity; $\mathrm{SO} 2$ emission reduction performance and economic growth effect contribute to green total factor productivity improvement by the path of promoting technological progress; and capital deepening contributes to green total factor productivity improvement by the path of enhancing scale effect and promoting technical efficiency improvement [21].

\section{Green TFP Theory of Huaihe Economic Zone under Big Data}

3.1. Analysis of TFP Formation and Regulatory Mechanisms. In order to grasp green total factor productivity fundamentally, this part analyzes green total factor productivity from the perspectives of formation mechanism, influencing factors, and regulation mechanism, in order to lay the foundation for the later research. This part includes the definition of green total factor productivity, the analysis of green total factor productivity formation mechanism, the analysis of green total factor productivity influencing factors, and the analysis of green total factor productivity regulation mechanism. Before analyzing the formation and regulation mechanism of green total factor productivity, we should first figure out what green total factor productivity is, that is, the definition of green total factor productivity. To this end, we start from the most basic productivity and define productivity, total factor productivity, and green total factor productivity in turn. Productivity, the ratio of output to input, 
measures the amount of output per unit of input. According to Marx, productivity is "the efficiency of productive activity in a given period of time." It reflects the quality of economic growth of a country or region. Based on the quantity of production factors reflected, we can divide it into single factor productivity and total factor productivity. Single factor productivity is the ratio of output to the input of a certain input factor, such as capital productivity and labor productivity. Labor productivity reflects the ratio of the output created by workers to the amount of labor consumed in a certain period of time. However, since single factor productivity reflects a single content, and there is a relationship between different single factor productivity, one single factor productivity alone cannot accurately evaluate the quality of economic growth. It is necessary to use total factor productivity to reflect the economic growth.

In the endogenous economic growth model, total factor productivity is the growth rate of output resulting from factor inputs other than labor and capital factor inputs. Generally speaking, total factor productivity, also known as the rate of technological progress, refers to the increase in production efficiency brought about by technological progress, organizational innovation, specialization, and production innovation, which is also the productivity of intangible factor inputs. If expanding reproduction is divided into external and internal expanding reproduction, the production efficiency of internal expanding reproduction is total factor productivity. The sustainable development of economy and the improvement of national wealth level are ultimately based on the improvement of total factor productivity. Due to the increasingly serious problems of resources and environment, scholars gradually put forward the concept of green total factor productivity from total factor productivity. Green total factor productivity is a measure of economic development from the perspective of good and fast economic development and sustainable development by adding the components of resources and environment on the basis of total factor productivity. From the connotation of total factor productivity, we can define green total factor productivity from two perspectives: firstly, from the perspective of green input, we can define green total factor productivity as the production efficiency of green technology; secondly, from the perspective of green output, we can define green total factor productivity as the green output efficiency of intangible production factor input. Considering the availability of relevant index data, the relevant research in this paper will be based on the output perspective.

The growth rate of green total factor productivity is often considered as an indicator of scientific and technological progress after considering environmental factors, which mainly comes from technological progress, specialization, organizational innovation, and production innovation. However, these input factors are usually intangible and cannot be directly expressed by specific variables and values, so this paper analyzes the formation mechanism of green total factor productivity from the perspective of green output. From the perspective of green output, the improvement of green output comes from the expansion of tangible factors of production inputs and the increase of intangible factors of production inputs, but intangible factors of production do not directly affect green output and thus have an impact on economic growth and green total factor productivity changes. Knowledge, technology, advanced management, and other factors that affect total factor productivity cannot bypass input factors and act directly on economic growth, nor can advanced technology that exists only in the laboratory or advanced management experience that exists in the classroom directly affect economic growth and total factor productivity changes. Therefore, this paper argues that intangible factors of production can only form productivity if they are parasitic on tangible factors of production, so green total factor productivity will also be formed on the input and use of tangible factors of production, and its parasitic tangible factors of production are labor and capital, and the specific formation mechanism is shown in Figure 1.

\subsection{Data Collection of Green TFP Based on Big Data.} Output is the variety of useful goods and services created in the production process, usually expressed as gross domestic product (GDP), which is the value of all final goods or services produced by a country or region in a certain period of time [22-24]. The disadvantage is that the GDP indicator does not take into account the factors of resources and environment in the accounting process. Therefore, this paper believes that it is more appropriate to use the green GDP indicator in the process of green total factor productivity measurement and adjustment. The green GDP indicator greens the current GDP indicator, and he deducts the cost of environmental resources and the service cost of environmental resource protection from the current GDP to represent the net positive effect of national economic growth, which is expressed as "GY" in this paper. Since only a few years of green GDP data have been published by official authorities in the Huaihe Economic Zone, measurement is required to obtain the full green GDP data for the study period of this paper. The academic community has not yet reached a consistent result on the measurement method of green GDP, and most of them adopt the physical quantityvalue quantity measurement path; however, there are still more controversies because of the valuation method involved in this path. In this paper, in order to avoid possible bias due to valuation issues, we adopt the method of subtracting the total investment in environmental pollution control from the GDP and consider the difference between the two as green GDP, with the following formula: 


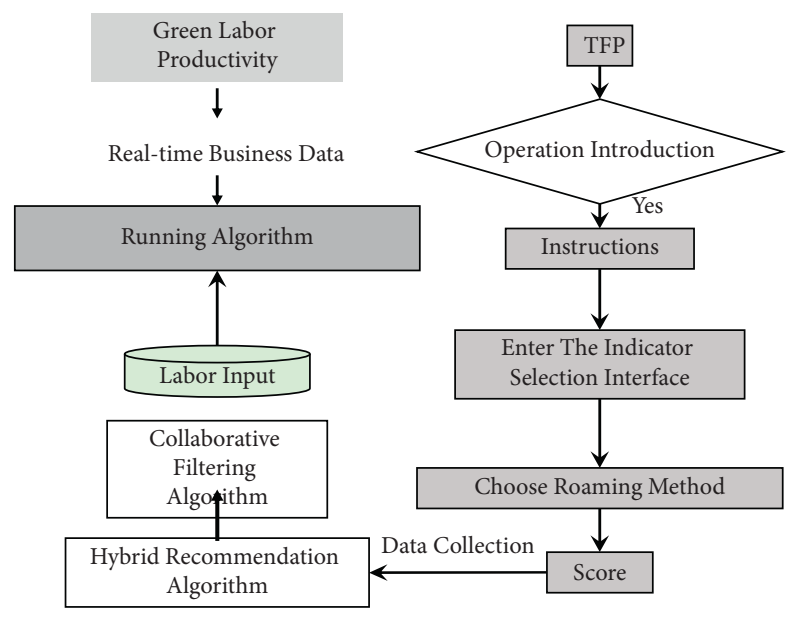

Figure 1: Analysis of the formation mechanism of green total factor productivity.

To avoid the effect of price factors, the relevant variables are converted to constant 1986 prices. Among them, the GDP data are converted by the GDP index, and the total investment in environmental pollution control is converted by the industrial producer ex-factory price index. The capital input in Solow's residual value method is an indicator of capital stock, which refers to the sum of all types of capital that has been invested in the enterprise during the production process. The capital stock plays an important role in economic development, but since the current statistics do not provide data on the capital stock of the whole society, it needs to be measured in order to use this indicator. The commonly accepted measurement method in existing studies is the perpetual inventory method. The basic idea is to take the sum of the residual value of the capital stock remaining after the current period's investment and the previous period's depreciation as the current period's capital stock. $t_{K}$ is the capital stock in year, $t K$ - is the capital stock in year $t-1$, and $t_{I}$ is the investment in year $t$.

$$
P(Y, X)=\frac{P(X, Y) / q(X)}{k+P(Y)} .
$$

Total social fixed asset investment is a unique statistical accounting indicator in China, which is not consistent with the SNA statistical system. Compared with the amount of social fixed asset investment, total fixed capital formation is broader in the definition of the scope of project investment, which includes not only tangible fixed assets, but also the increase of intangible fixed assets, which is closer to the purpose of this paper and is consistent with the international common fixed asset investment index.

$$
V \text { map }=\frac{\left\{a_{1}, a_{2}, a_{3} \ldots a_{n}\right\}}{\max P(X, Y)} .
$$

Therefore, the total fixed capital formation is chosen as the indicator of investment $t_{I}$ in year $t$ in this paper. To avoid the influence caused by price factors, the relevant variables are still converted to 1986 constant prices. Since the country only started to publish the price index of fixed asset investment from 1990, its quantity differs a lot from the data of the sample period studied in this paper, and there are different opinions about the selection of the price index before 1990, and no scientific and uniform standard has been formed.

$$
V_{n p}=\frac{\arg v_{j}\left\{a_{1}, a_{2}, a_{3} \ldots a_{n}\right\}}{\prod P(X, Y)} .
$$

Therefore, this paper believes that it is more reasonable to maintain consistency with the selection of investment indicators and choose the index of gross fixed capital formation in total capital formation as the price index variable in this paper.

Output elasticity is the relative change in output corresponding to a relative change in the input of a factor when the level of technology, input prices, and other inputs are held constant. This paper deals with output elasticities as the input-output elasticity of capital and the input-output elasticity of labor, respectively. In the green total factor productivity measure, the coefficient of input-output elasticity of capital is the relative change of green output caused by the relative change of capital input when the technology level, input price, and labor input are kept constant. The input-output elasticity coefficient of labor is the relative change of green output caused by the relative change of labor input when the technology level, input price, and capital input are kept constant. The input-output elasticity coefficient of capital is generally expressed as " $X$ ". The inputoutput elasticity coefficient of labor is generally denoted by "Y".

$$
P_{x, y}=\frac{N \sum_{i=1}^{n} X * Y}{\sqrt{\sum_{i=1}^{n}(X+Y)}} .
$$

Based on the previous analysis, this paper uses interest rates and wages as the entry points for the causal and moderating analysis of green total factor productivity.

$$
Q(Y, X)=\frac{P(X, Y)}{q(X)} .
$$

Therefore, the causal and moderating data definitions include interest rate data definition and wage data definition, input-output elasticity coefficient of output per unit of deposit interest rate to total output, and inputoutput elasticity coefficient of output per unit of wage to total output data definition. Among them, both interest rate data and wage data are involved in the analysis of the causes and regulation of green total factor productivity. The interest rate is the ratio of the amount of interest to the principal in a certain period of time, and he indicates the level of interest per unit of money per unit of time, and the interest rate calculated on an annual basis is the annual interest rate. Interest rates can be divided into deposit rates and loan rates, depending on the banking business. The so-called deposit rate is the ratio of the interest earned on a deposit with a financial institution to the principal. The interest rate on a loan is the ratio of the interest paid on a loan at a financial institution to the principal. Interest rates can be divided into nominal and 
real interest rates depending on the relationship with inflation. The nominal interest rate is the interest rate that includes the inflation factor, while the real interest rate is the interest rate that excludes the inflation factor. Interest rate is one of the most important tools for macroeconomic regulation in each country, which can regulate monetary policy and also control investment, unemployment rate, etc. Therefore, it plays an important role in the analysis of the causes and regulation of green total factor productivity. In the selection of indicators, in this paper, on the one hand, we study the overall green total factor productivity of the country, and on the other hand, in order to avoid the influence of more negative values in the real interest rate, the one-year nominal deposit rate variable is chosen as the interest rate indicator of this paper, denoted by " $R$ ".

3.3. Model Testing. To ensure that the constructed model is economically realistic and valid, we use the data compiled above to test the validity of the model. To facilitate the variable description and the implementation of the testing process, the relevant variables are first defined symbolically, and then the validity tests are conducted for the measurement model, the causal model, and the conditioning model. If there is no stable cointegration relationship between a set of nonstationary time series, the regression model constructed by this set of time series may have pseudoregression. Therefore, the smoothness of the time series in the model should be tested first. If the time series are smooth, a stable cointegration relationship exists between the variables; if they are not smooth, they need to be differenced, and then the smoothness of the model should be tested, as shown in Figure 2. The smoothness test used in this paper is the ADF unit root test. If the mean, variance, and self-covariance of the time series do not depend on time $t$, but only on the length of the interval between two observations, then we say that this time series is a smooth time series. The results of the unit root test show that the ADF unit root test statistics of the green total factor productivity growth rate, green GDP growth rate, capital stock growth rate, and employment growth rate in the measurement model reject the original hypothesis at the $5 \%$ test level, and there is no unit root, which is a smooth time series. In the test, the correlation coefficients of and are statistically significant, then it can be said that "it is caused by Granger"; that is, it is the cause of Granger. In this case, the model setup is reasonable and can be used for analysis (Figure 2). The test procedure of the moderated model is the same as that of the measured model, including the ADF unit root-based stationarity test and Granger causality test.

The results of the ADF unit root test of the relevant variables of the measurement model show that the green GDP growth rate, capital stock growth rate, and employment growth rate reject the original hypothesis that they are not the Granger causes of the green total factor productivity growth rate, indicating that all three variables are the Granger causes of the green total factor productivity growth rate. The measurement model is reasonably constructed and can be used to measure the green total factor productivity growth rate of Huaihe Economic Zone. The causal model involves three variables: green total factor productivity growth rate, deposit interest rate growth rate, and average wage growth rate of urban units of employment. Therefore, to avoid pseudoregression, we still conduct the ADF unit root-based stationarity test on the relevant variables, and the test results are shown in Figure 3. The results of the study show that the traditional efficiency evaluation without considering energy, environment, and human capital is significantly distorted, and the green total factor productivity of industry in most provinces is significantly improved by the rate of technological progress.

The results of the ADF unit root test of the variables related to the causal analysis show that the ADF unit root test statistics of the growth rate of green total factor productivity, the growth rate of deposit interest rate, and the growth rate of the average wage of employed persons in urban units in the causal analysis reject the original hypothesis at the $5 \%$ test level, and there is no unit root, which is a smooth time series. Therefore, we can construct a general regression model for the analysis of the causes of green total factor productivity. Therefore, we use EViews 8.0 software to test the green total factor productivity growth rate as the dependent variable, and the growth rate of deposit interest rate and the growth rate of average wage of employed urban workers as the independent variables. The results of the causal model and the related variables show that the coefficients of the growth rate of deposit interest rate and the growth rate of the average wage of employed urban workers in the model are positive and consistent with the actual situation. The $p$ values of the $t$-statistics of the growth rate of deposit interest rate and the growth rate of the average wage of employed persons in urban units can pass the test of $10 \%$ significance level. In addition, the $p$ value of the $F$-statistic of the model is 0.01 , which can also pass the validity test. Therefore, the model is reasonably set up and can analyze the causes of green total factor productivity with the general regression model constructed by using the green total factor productivity growth rate as the dependent variable and the growth rate of deposit interest rate and the growth rate of average wage of employed urban workers as the independent variables. Since the variables involved in the conditioning model are the same as those involved in the causality analysis, and the results of the ADF unit root test of the variables involved in the causality analysis already show that the growth rate of green TFP, the growth rate of deposit interest rate, and the growth rate of average wage per urban unit of employment are all stationary time series, therefore, only the Granger causality of the relevant variables in the model needs to be tested in the moderated model test. 


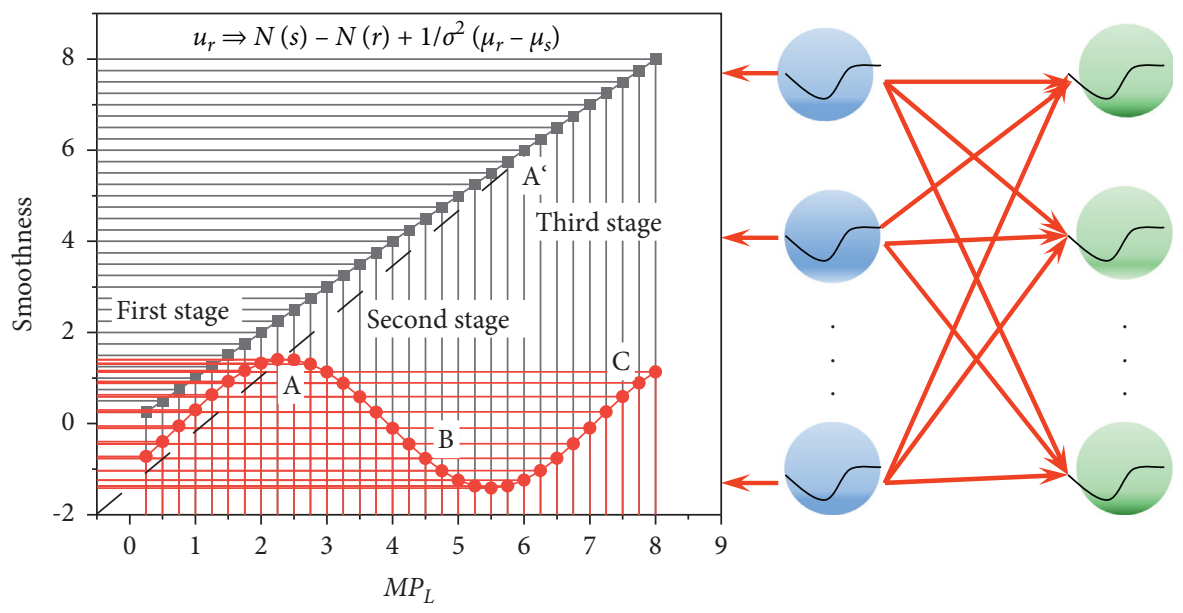

Figure 2: Validation of model smoothness.

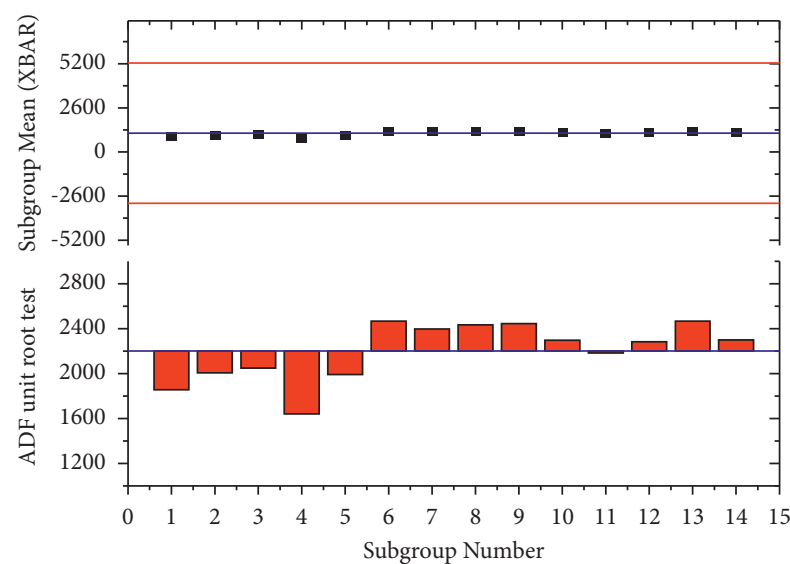

FIGURE 3: Results of ADF unit root test for variables of interest in the causal analysis.

\section{Empirical Analysis}

To further investigate the level of green total factor productivity in the Huaihe Economic Zone and the causes of this level, and to regulate it more scientifically and rationally, this chapter conducts an empirical analysis based on the constructed model and the collated data. The empirical analysis consists of four main parts, which are the measurement of green total factor productivity, the evaluation of rationality, the analysis of causes, and the analysis of regulation. We have constructed the measurement model of green total factor productivity based on the relevant theories and mechanism analysis and tested its validity, and the data related to the model have been collated. The green GDP growth rate, capital stock growth rate, labor force growth rate, and input-output elasticity coefficient of capital and input-output elasticity coefficient of labor collated above are substituted into the measurement model, and the results of green total factor productivity growth rate are shown in Figure 4.

In order to visualize the level of green total factor productivity growth rate in Huaihe Economic Zone from 1987 to 2015, its trend, and its relationship with other variables, we present the green total factor productivity growth rate, green GDP growth rate, capital stock growth rate, and employment growth rate in the form of Figure 5. By analyzing the overall situation of green total factor productivity growth rate in the Huaihe Economic Zone from 1987 to 2015, we find that, overall, the green total factor productivity growth rate in the Huaihe Economic Zone is still at a relatively low level, with negative growth rates in $1989,1990,1998$, and 1999. The green TFP growth rate in the rest of the years from 1987 to 2015 is below 5\%, and the value of green TFP growth rate in most years is between $0 \%$ and $1 \%$. From the trend of change, the green TFP growth rate of Huaihe Economic Zone from 1987-2015 shows fluctuations of up and down, and the fluctuations vary in different time periods. By analyzing its trend, we divide it into four stages, namely, 1987-1995, 1996-2004, 2005-2010, and 2011-2015. The green TFP growth rate starts to pick up in 1991 and reaches its maximum in 1992 and then starts to fall in 1993 and gradually enters the next phase of green TFP fluctuation. In the period of 1996-2004, the green TFP growth rate is relatively stable and does not show large fluctuations. However, the values are low, $-0.51 \%$ and $-0.23 \%$ in 1998 and 1999 , respectively, and between $0 \%$ and $1 \%$ in 1996, 1997, and 2000-2004. The green TFP growth rate gradually increased in 2006 and reached the second largest value in the study period, $5.79 \%$, in 2007 , and then declined in 2008 , but its value was still above 0 . In general, the level of green TFP growth rate in the Huaihe Economic Zone is more desirable in this period (Figure 5).

Through the analysis of green total factor productivity in general and at each stage, it is easy to find that the current level of green total factor productivity in Huaihe Economic Zone is low and fluctuates up and down. Moreover, the growth rate of green total factor productivity in Huaihe Economic Zone has been decreasing in recent years, which means that the growth rate of green total factor productivity in Huaihe Economic Zone is slowing down in recent years from another aspect. By analyzing and observing Figure 6, we can find that green TFP and green GDP growth rate are both interdependent and influence each other. The relationship between the two is divided into four stages. The 

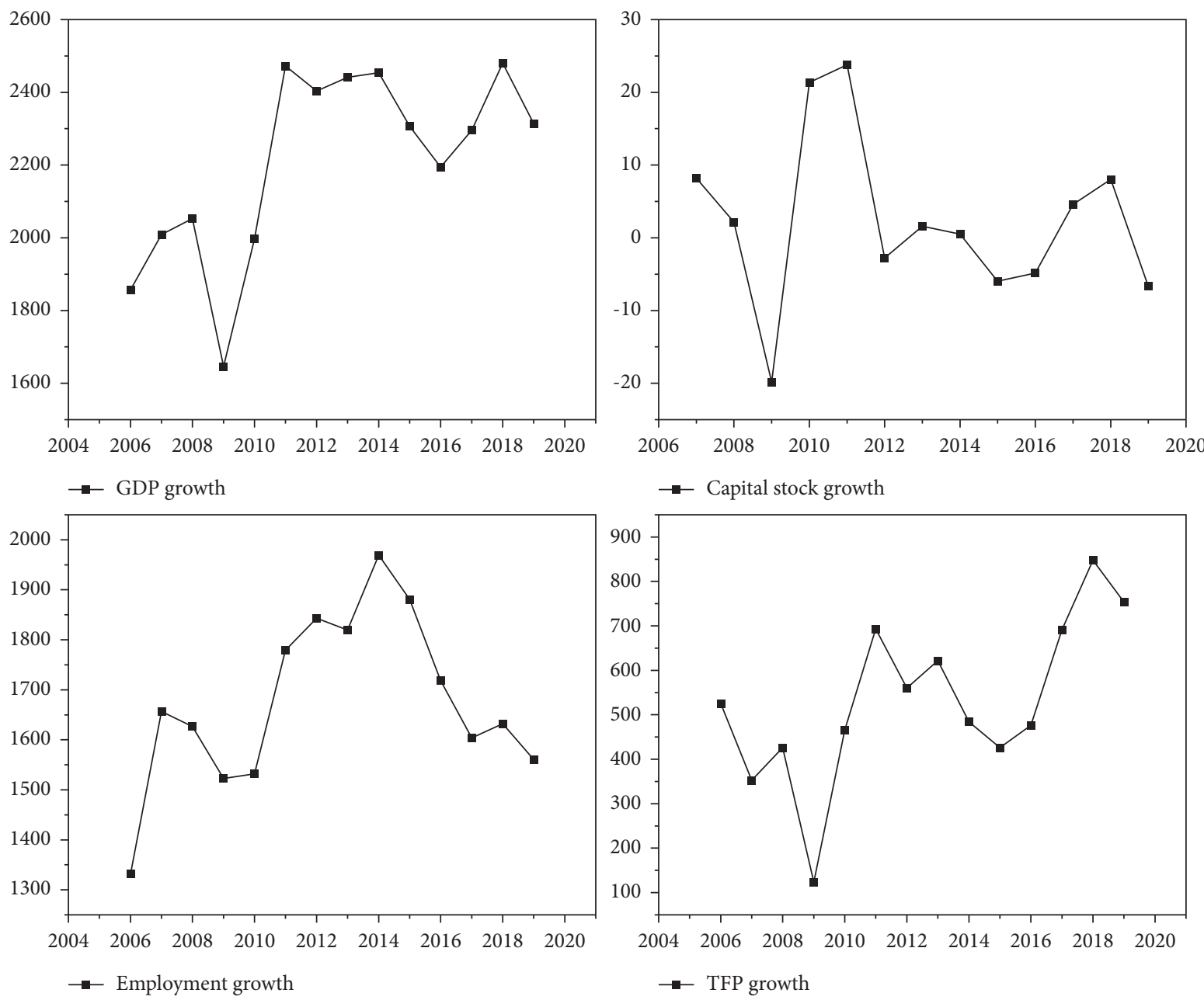

FIgURE 4: Green total factor productivity growth data.

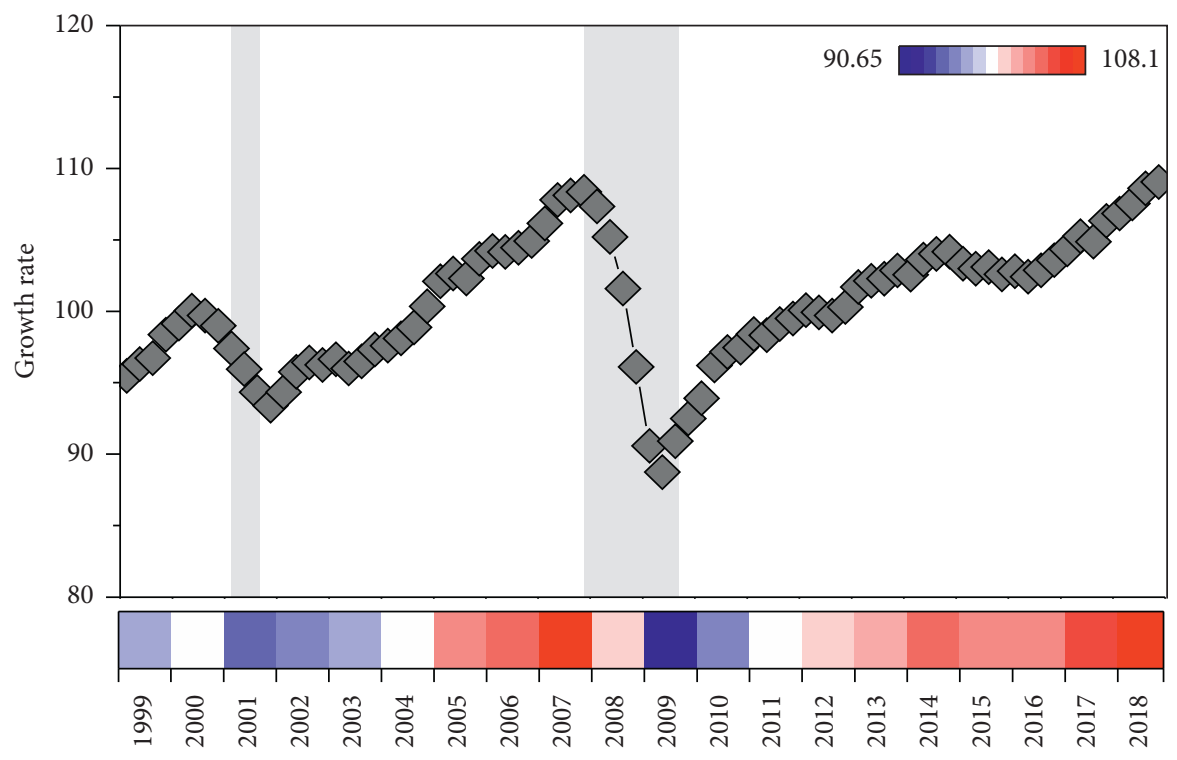

Figure 5: Trend of growth rate. 


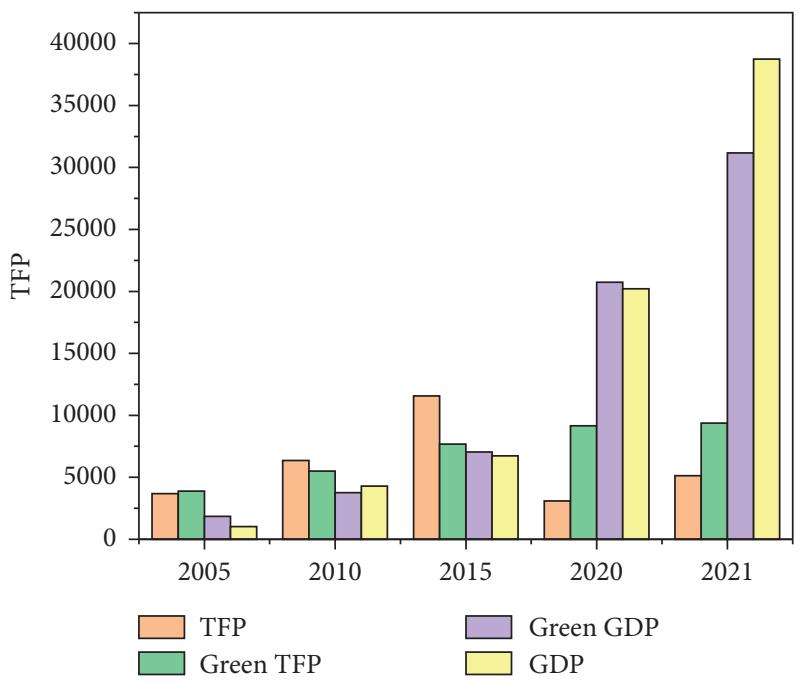

FIGURE 6: Relationship between green total factor productivity and green GDP growth rate.

green total factor productivity growth rate and the green GDP growth rate both fluctuated significantly during this period, reaching the lowest value in 1990, with the lowest value of $2.40 \%$ for the green total factor productivity growth rate and $3.91 \%$ for the green GDP growth rate. Both the green TFP growth rate and the green GDP growth rate reached their maximum values in 1992, at $6.77 \%$ and $14.28 \%$, respectively. The average value of green total factor productivity growth rate in this period is $1.76 \%$, and the average value of green GDP growth rate is $10.25 \%$ (Figure 6).

Through the analysis, it is found that the green total factor productivity growth rate and the green GDP growth rate in Huaihe Economic Zone from 1987 to 2015 have a high degree of positive correlation. On the one hand, the green GDP growth rate is also higher at the time points where the green total factor productivity growth rate is higher, and the green GDP growth rate is also lower at the time points, where the green total factor productivity growth rate is lower, and both reach the maximum and minimum values in the same year. On the other hand, the mean values of green TFP growth rate and green GDP growth rate also show the same movement, and the mean values of green GDP growth rate are also higher at the time points, where the mean values of green TFP growth rate are higher, and the rising and falling trends are the same. This shows that the change of green total factor productivity will drive the change of green GDP, and the change of green GDP will also stimulate the enterprises to adjust their production and management methods, which will affect the green total factor productivity. The contribution of different production factor growth rates to the green GDP growth rate directly determines the economic development of the Huaihe Economic Zone. If the green GDP growth rate relies more on the factor growth rate, then the growth mode is sloppy; if the green GDP growth rate relies more on the green total factor productivity growth rate, then the growth mode is intensive. So, what is the type of economic growth in the Huaihe Economic Zone at present? This requires us to analyze the contribution of different production factor growth rates to

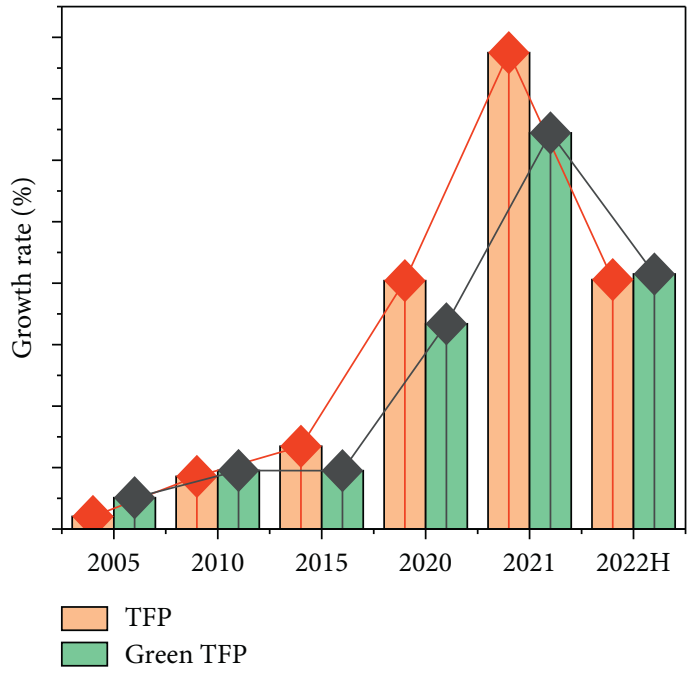

FigURe 7: TFP growth rate.

the green GDP growth rate. Figure 7 shows that, from 1987 to 2015 , the green total factor productivity growth rate in the Huaihe Economic Zone was much lower than the green GDP growth rate, and the capital stock growth rate was higher compared with the growth rate of employed persons. The average growth rate of green GDP, the average growth rate of capital stock, the average growth rate of employed persons, and the average growth rate of green total factor productivity in Huaihe Economic Zone in this period are $9.69 \%, 11.12 \%, 1.47 \%$, and $1.47 \%$, respectively. In terms of the average growth rate, the growth rate of capital stock is still much higher than the growth rate of green total factor productivity and the growth rate of employed persons (Figure 7).

Figure 8 shows that when the deposit rate growth rate and the green TFP growth rate change simultaneously, the average wage growth rate is generally smaller than when only the green TFP growth rate changes. A cross-sectional look at the data in Figure 8 shows that when the deposit rate is set to 


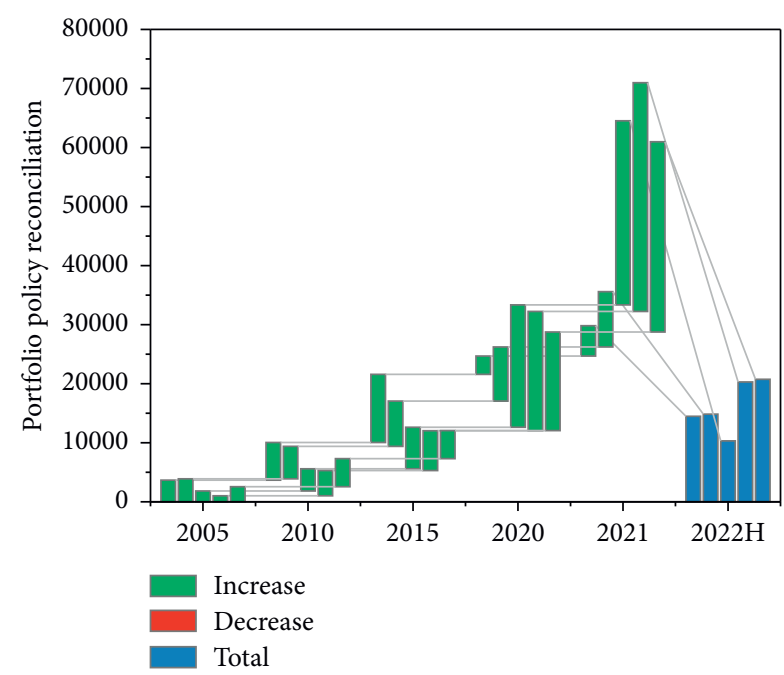

FIgURE 8: Portfolio policy reconciliation data table.

a fixed value, the average wage growth rate still increases as the green TFP growth rate increases. Longitudinally, as the interest rate growth rate increases, the average wage growth rate decreases at the same green TFP growth rate level. When the growth rate of the deposit rate is $15 \%$, the average wage growth rate at the green TFP growth rate of $2 \%$ to $8 \%$ is negative. Therefore, when using a combination of policy adjustment, we should pay attention to the strength of interest rate policy and wage policy (Figure 8).

\section{Conclusion}

In the theoretical analysis, the role of carbon cycle in the ecoeconomic circle is discussed under the coordinated development of the ecosystem and economic system of Huaihe Economic Zone, and a theoretical analysis is carried out from economic growth theory, green economy, circular economy, low carbon economy theory, and total factor productivity theory, and the relationship between carbon sink and gross local growth value and green total factor productivity is clarified through theory and empirical evidence. In the empirical part, a more comprehensive carbon sink and $\mathrm{CO}_{2}$ emission measurement system is established from the perspectives of energy consumption, industrial production process, agricultural production process, forest, etc. After measuring the traditional TFP based on the expected output gross local product through the superefficient SBM-Global-Malmquist-Luenberger index model and the ecological TFP that integrates the expected output carbon sink and gross local product. The ecological TFP based on the expected output of local GDP and the ecological TFP based on the expected output of carbon sink and local GDP were measured by the superefficient SBM-Global-Malmquist-Luenberger index model and compared from the perspective of time series and regional differences. After that, the spatial Durbin model is used to analyze the direct and indirect effects of each variable on TFP, using TFP measured from an ecological perspective as the explanatory variable and economic development level, environmental regulation, research level, industrial structure, and infrastructure as explanatory variables. As the final chapter, this chapter provides a comprehensive summary of the above analysis results, and on this basis, it proposes specific countermeasures to improve the green total factor productivity based on the carbon cycle and finally explains and makes an outlook on the shortcomings of the content. The change trend of both traditional TFP and ecological TFP is the same, with the implementation of the scientific concept of development, the economic development is faster, and the green total factor productivity increases dramatically; after the shock, they both decline rapidly, and the country invests capital to stimulate the economy, which ushers in a short rebound. Entering the "new normal" requires high-quality development, and the ecological technological progress appears to be a continuous growth phenomenon.

According to the research framework of this paper, the model tests are divided into interest rate policy adjustment model test, wage policy adjustment model test, and portfolio policy adjustment model test.

\section{Data Availability}

The data used to support the findings of this study are included within the article.

\section{Conflicts of Interest}

No competing interests exist concerning this study.

\section{References}

[1] F. Abbasi, M. Mokhtari, and M. Jalili, "The impact of agricultural and green waste treatments on compost quality of dewatered sludge," Environmental science and pollution research, vol. 26, no. 35, pp. 35757-35766, 2019.

[2] S. M. S. Ardebili, "Green electricity generation potential from biogas produced by anaerobic digestion of farm animal waste and agriculture residues in Iran," Renewable Energy, vol. 154, pp. 29-37, 2020.

[3] U. L. C. Baldos, F. G. Viens, T. W. Hertel, and K. O. Fuglie, "R\&D spending, knowledge capital, and agricultural productivity growth: a bayesian approach," American Journal of Agricultural Economics, vol. 101, no. 1, pp. 291-310, 2019.

[4] C. A. Bartel, S. V. Archontoulis, A. W. Lenssen et al., "Modeling perennial groundcover effects on annual maize grain crop growth with the agricultural production systems sIMulator," Agronomy Journal, vol. 112, no. 3, pp. 1895-1910, 2020.

[5] D. A. Becker, M. H. E. M. Browning, M. Kuo, and S. K. V. D. Eeden, "Is green land cover associated with less health care spending? promising findings from county-level medicare spending in the continental United States," Urban Forestry and Urban Greening, vol. 41, pp. 39-47, 2019.

[6] L. F. Chen, "Green certification, e-commerce, and low-carbon economy for international tourist hotels," Environmental science and pollution research, vol. 26, no. 18, pp. 17965-17973, 2019.

[7] M. A. Ferrag, L. Shu, X. Yang, A. Derhab, and L. Maglaras, "Security and Privacy for Green IoT-based agriculture: review,blockchain solutions, and challenges," Ieee Access, vol. 8, pp. 32031-32053, 2020. 
[8] Q. Geng, Q. Ren, R. H. Nolan, P. Wu, and Q. Yu, “Assessing China's agricultural water use efficiency in a green-blue water perspective: a study based on data envelopment analysis," Ecological Indicators, vol. 96, pp. 329-335, 2019.

[9] J. M. H. Green, S. A. Croft, A. P. Durán et al., "Linking global drivers of agricultural trade to on-the-ground impacts on biodiversity," Proceedings of the National Academy of Sciences, vol. 116, no. 46, pp. 23202-23208, 2019.

[10] C. Guo, Z. Bai, X. Shi et al., "Challenges and strategies for agricultural green development in the yangtze river basin," Journal of Integrative Environmental Sciences, vol. 18, no. 1, pp. 37-54, 2021.

[11] Z. Huang, M. Hejazi, Q. Tang et al., "Global agricultural green and blue water consumption under future climate and land use changes," Journal of Hydrology, vol. 574, pp. 242-256, 2019.

[12] M. Kansanga, P. Andersen, D. Kpienbaareh et al., "Traditional agriculture in transition: examining the impacts of agricultural modernization on smallholder farming in Ghana under the new green revolution," The International Journal of Sustainable Development and World Ecology, vol. 26, no. 1, pp. 11-24, 2019.

[13] A. Karunarathne, D. Gunnell, F. Konradsen, and M. Eddleston, "How many premature deaths from pesticide suicide have occurred since the agricultural green revolution?” Clinical Toxicology, vol. 58, no. 4, pp. 227-232, 2020.

[14] Y. Li, J. Wang, X. Han et al., "Coupling between the grain for green Program and a household level-based agricultural ecoeconomic system in ansai, shaanxi province of China," Journal of arid land, vol. 12, no. 2, pp. 199-214, 2020.

[15] Y. Liu and C. Feng, "What drives the fluctuations of "green" productivity in China's agricultural sector? a weighted russell directional distance approach," Resources, Conservation and Recycling, vol. 147, pp. 201-213, 2019.

[16] M. Ollenburger, T. Crane, K. Descheemaeker, and K. E. Giller, "Are farmers searching for an african green revolution? exploring the solution space for agricultural intensification in southern Mali," Experimental Agriculture, vol. 55, no. 2, pp. 288-310, 2019.

[17] A. O. Bobea, T. R. Ault, C. M. Carrillo, R. G. Chambers, and D. B. Lobell, "Anthropogenic climate change has slowed global agricultural productivity growth," Nature Climate Change, vol. 11, no. 4, pp. 306-312, 2021.

[18] B. Pandey, Q. Zhang, and K. C. Seto, "Time series analysis of satellite data to characterize multiple land use transitions: a case study of urban growth and agricultural land loss in India," Journal of Land Use Science, vol. 13, no. 3, pp. 221-237, 2018.

[19] J. F. Schyns, A. Y. Hoekstra, M. J. Booij, R. J. Hogeboom, and M. M. Mekonnen, "Limits to the world's green water resources for food, feed, fiber, timber, and bioenergy," Proceedings of the National Academy of Sciences, vol. 116, no. 11, pp. 4893-4898, 2019.

[20] H. E. Weichun, L. I. Erling, and C. Zhizhen, "Evaluation and influence factor of green efficiency of China's agricultural innovation from the perspective of technical transformation," Chinese Geographical Science, vol. 31, no. 2, pp. 313-328, 2021.

[21] P. Buckley, S. Noonan, C. Geary, T. Mackessy, and E. Nagle, "An empirical study of gamification frameworks," Journal of Organizational and End User Computing, vol. 31, no. 1, pp. 22-38, 2019.

[22] A. Shahri, M. Hosseini, K. Phalp, J. Taylor, and R. Ali, "How to engineer gamification," Journal of Organizational and End User Computing, vol. 31, no. 1, pp. 39-60, 2019.
[23] K.-C. Chang and Y. M. Seow, "Protective measures and security policy non-compliance intention," Journal of Organizational and End User Computing, vol. 31, no. 1, pp. 1-21, 2019.

[24] L. Yue, W. Jijun, H. Xiaoning, and Z. Xiaocui, "Synergic relationship between the grain for green program and the agricultural eco-economic system in ansai county based on the VAR model," Journal of resources and ecology, vol. 12, no. 2, pp. 292-301, 2021. 